\title{
Exciting Research Studies on Practical Medical Problems and Health Services Delivery
}

\author{
Marjorie A. Bowman, MD, MPA, and Anne Victoria Neale, PhD, MPH (J Am Board \\ Fam Med 2011;24:221-223.)
}

Major articles with major findings are in this issue. Patient-centered medical care is associated with large decreases in medical care costs! Pelvic examinations can lead to increased symptoms and infections. What should we do? Maternal postpartum depression is related to poorer infant health care quality of life at least until 16 months of age, but cannot be detected until well into the immediate postpartum time period. Using the Colorado Asthma toolkit, practices can significantly improve their management of asthma. Smoking has implications for asthma and its management. Healthy patients often do not understand their insurance, nor why they need it if they are healthy. Younger women are not aware of the potential teratogenic harms of their diabetes and hypertension medicines. Insomnia patients often will accept behavioral treatments. A health literacy screening was not of much practical help in one office. Obesity should be a documented medical problem and is an accepted topic for group medical visits.

\section{Patient-Centered Care Lowers Medical Costs}

News flash: patient-centered care is associated with less use of health care services and lower medical expenditures. ${ }^{1}$ There was a fairly dramatic difference in charges: $50 \%$. When controlling for multiple other factors, more patient-centered care was associated with a $15 \%$ (for women patients) and $31 \%$ (for men) decrease in cost over the ensuing year; it is interesting to note the sex difference. Impressively, the decreased utilization was diffuse across specialty visits, ancillary testing, and even hospitalization despite the relatively small number of patients $(\mathrm{n}=509)$. The physicians were secondand third-year residents, so perhaps the differences would not be as great if they were attending phy-

Conflict of interest: The authors are editors of the JABFM. sicians. Increasing the ability of physicians to provide patient-centered care could decrease costs, providing more dollars to care for those who are currently underserved.

\section{What Are the Negative Effects of a Pelvic Examination?}

What about urinary symptoms or urinary tract or vaginal infections? We do so many pelvic exams, but mostly we think of emotional consequences, such as women fearing the examination itself or the possible results (diagnosis of sexually transmitted diseases or an abnormal Papanicolaou smear). However, Tiemstra et $\mathrm{al}^{2,3}$ present new data that suggest that women have more urinary symptoms (prospective and retrospective study), more vaginal symptoms (retrospective study), and are more likely to have actual urinary tract infections (retrospective chart review). The authors' points were reinforced when I (MAB) recently saw 2 patients with urinary tract infections that they blamed on recent pelvic exams. More study needs to be done, but these results are intriguing and suggest we need more work on whether pelvic exams cause problems and how to prevent such negative outcomes.

\section{Asthma, Smoking, and Steroid Dosing}

That smoking has negative effects on asthma would seem to be obvious and well known to physicians and (probably) patients alike. That children with intrauterine exposure to smoke have a higher rate of asthma may not be surprising, but is probably not as well known. Were you aware that steroid resistance occurs more often in asthma patients who smoke compared with asthma patients who do not smoke? ${ }^{4}$ The data for this are reasonably clear and suggest that smoking asthmatic patients will respond to higher doses of steroids, when indicated. Overall, as family physicians we need to help our patients stop smoking, be aware of and work to 
eliminate secondhand smoke, and be aware that higher doses of steroids may be needed to gain effect in patients with asthma.

To help family physician practices with asthma care, the Colorado Asthma Toolkit Program was disseminated in 57 rural Colorado practices. ${ }^{5}$ Practice coaches were used, a spirometer was given to the practices, and an interactive voice response program was created and provided. Through this ambitious program, these practices reported large increases in their appropriate diagnosis and management of asthma. Impressive! Providing physician offices with sufficient support and materials can make a large difference in improving patient care.

\section{Infants Suffer When Maternal Postpartum Depression Occurs}

Postpartum depression is associated with a number of negative outcomes for infants, including less preventive care and more acute care. Grzywacz et $\mathrm{al}^{6}$ report a 16-month postpartum longitudinal follow-up of employed women. The depressed mothers reported more infant pain, more infant gastrointestinal illness, and more concern for the health of their infants. In a related article, Pawar et $\mathrm{al}^{7}$ screened for postpartum depression shortly after birth in an attempt to determine the utility of screening before discharge from the hospital. So few mothers were positive, and these were underrepresentative of later postpartum depression, that the immediate antenatal period is not the ideal time for screening albeit convenient.

\section{Lack of Discussion on Teratogenicity}

In a startling reminder, Morrical-Kline et $\mathrm{al}^{8}$ found that the use of angiotensin-converting enzyme inhibitors, angiotensin-receptor blockers, and HMG-coenzyme A reductase inhibitors is common in women of childbearing age without adequate documentation of provider discussion with patients about the appropriate birth control, even with the availability of computerized medical record decision support and even when the providers were given a list of their patients of childbearing age who were taking these drugs. With increasing rates of obesity, hypertension, and diabetes, the indications for these drugs in younger women has increased; now we need to make sure that these patients are adequately protected from pregnancy or that we choose other medications more favorable for pregnancy.

\section{Patients Do Not Understand Insurance}

In a follow-up article to one previously published in The fournal of the American Board of Family Medicine that reported on the development of an innovative access program for uninsured patients involving a reduced-fee retainer program, ${ }^{9}$ Saultz et al ${ }^{10}$ present findings of interviews with the patients. Similar to patients with regular insurance, the patients were not always sure why they should re-enroll if they were healthy and they did not fully understand how the plan worked, yet were generally appreciative of the care and the opportunity to have health insurance. Though more variations on retainer fees related to primary care are being seen nationally, doing so for those without insurance is a tremendous advance, yet still uncommon.

\section{Health Literacy Screening of Unclear Practical Help}

In one office, ${ }^{11}$ an attempt to implement a health literacy instrument was not particularly sustainable, probably at least partly because its value in the clinical setting was elusive.

\section{Patients Accept Both Behavioral and Medication Treatments for Insomnia}

Bluestein $^{12}$ looked at factors associated with the acceptance of behavioral treatments for insomnia. Medication may seem like an easier answer for both patients and physicians, but behavioral treatments would seem to be preferable because they may require relatively short-term effort for long-term impact, even a "cure," whereas medicine is often not a cure and requires long-term use to continue effectiveness. Just as with many other behaviors, lack of confidence in one's ability to make changes are inhibitory. Bluestein et $\mathrm{al}^{12}$ found that patients' willingness to take medication and willingness to accept behavioral treatment are not mutually exclusive. Thus, a patient who comes in requesting medication may well be willing to try behavior strategies. Depression was not a significant predictor one way or another. Bottom line: do not presume whether patients will or will not accept behavioral treatments for insomnia, and consider helping them boost their own confidence in their ability to change. 


\section{Research Letters about Obesity}

Stephens ${ }^{13}$ notes that obesity is often not noted as a coded problem in military medical records. Though the rate of obesity with $\mathrm{BMI}>30(15 \%)$ was lower than that of the general public, the provider's notation or coding of this as a problem was also very low $(16 \%)$. The theory is that this problem is less likely to be addressed by the physician and/or patient if it is not given a diagnostic code and listed on the problem sheet. Palaniappan et $\mathrm{al}^{14}$ report on an individual physician successfully providing shared medical appointments for weight loss.

\section{Reflection}

A little more than a year after the Haitian earthquake disaster, Cook $^{15}$ tells a poignant story of trying to save a baby against great odds. This reflection reminds us again of the big hearts of our colleagues.

\section{PBRN Theme Issue}

Please stay tuned for our annual practice-based research network theme issue, which will be published in the first week of September. We received a great response to our call for papers for this special issue and we look forward to sharing with you the groundbreaking research that is being done in this area. This will be our best practice-based research network issue yet!

Marjorie A. Bowman, MD, MPA

Anne Victoria Neale, PhD, MPH

\section{References}

1. Bertakis KD, Azari R. Patient-centered care is associated with decreased healthcare utilization. J Am Board Fam Med 2010;24:229-239.

2. Tiemstra JD, Pela E. Urinary symptoms after a routine pelvic exam. J Am Board Fam Med 2010; 24:290-295.

3. Tiemstra JD, Chico PD, Pela E. Genitourinary infections after a routine pelvic exam. J Am Board Fam Med 2010;24:296-303.
4. Stapleton M, Howard-Thompson A, George C, Hoover RM, Self TH. Smoking and asthma. J Am Board Fam Med 2010;24:313-322.

5. Bender BG, Dickinson P, Rankin A, Wamboldt FS, Zittleman L, Westfall JM. The Colorado Asthma Toolkit Program: a practice coaching intervention from the High Plains Research Network. J Am Board Fam Med 2010;24:240-248.

6. Darcy JM, Grzywacz JG, Stephens RL, Leng I, Clinch CR, Arcury TA. Maternal depressive symptomatology: 16-month follow-up of infant and maternal health-related quality of life. J Am Board Fam Med 2010;24:249-257.

7. Pawar G, Wetzker C, Gjerdingen D. Prevalence of depressive symptoms in the immediate postpartum period. J Am Board Fam Med 2010;24:258-261.

8. Morrical-Kline KA, Walton AM, Guildenbecher TM. Teratogen use in women of childbearing potential: an intervention study. J Am Board Fam Med 2010;24:262-271.

9. Saultz JW, Brown D, Stenberg S, et al. Access Assured: a pilot program to finance primary care for uninsured patients using a monthly enrollment fee. J Am Board Fam Med 2010;23:393-401.

10. Saultz JW, John Heineman J, Seltzer R, Bunce A, Spires L, DeVoe J. Uninsured patient opinions on a reduced-fee retainer program at academic health center clinics. J Am Board Fam Med 2010;24:304312.

11. Welch VL, VanGeest JB, Caskey R. Time, costs, and clinical utilization of screening for health literacy: a case study using the Newest Vital Sign (NVS) instrument. J Am Board Fam Med 2010;24: 281-289.

12. Bluestein D, Healey AC, Rutledge CM. Acceptability of behavioral treatments for insomnia. J Am Board Fam Med 2010;24:272-280.

13. Stephens MB. Coding and obesity: room to grow. J Am Board Fam Med 2010;24:329-330.

14. Palaniappan LP, Muzaffar AL, Wang EJ, Wong EC, Orchard TJ. Shared medical appointments: promoting weight loss in a clinical setting. J Am Board Fam Med 2010;24:326-328.

15. Cook JS. Night transport in Port-au-Prince. J Am Board Fam Med 2010;24:323-325. 